less well understood! Yet, probably well under $5 \%$ of these marine scientists are engaged in fish-rearing work, even in the widest sense!

Lastly, it will be obvious that even if scientific and technical solutions are found for any particular rearing project, and this is then approved for 'development', success at that or the production stage must in fact depend on economic factorswhether the product (either as a luxury article or as a serious contribution to the shortage of protein) can be produced economically. In any particular project this should be borne in mind from the beginning and re-assessed periodically, especially if the object is to provide cheap food to relieve malnutrition.

\title{
Ecological problems of marine fish farming
}

\section{By J. H. Steele, Marine Laboratory, Aberdeen}

Basically, farming of any kind involves two simultaneous changes. There is, firstly, a change in the environment when an area is enclosed. Secondly, there has to be a change in the behaviour of the stock to take advantage of the enclosed area. On land much of this two-way adaptation has taken place over very long periods of time, although in recent years, with selective breeding and with battery rearing, the rate of adaptation has become very much quicker. For fish farming, a similar long-term process has taken place in the tropics and with freshwater fish where fish farms are well established. In temperate regions, however, where we are now thinking about the possibilities of marine fish farming, we are only at the beginning. Apart from fish kept in aquaria, and the tank rearing work described in this symposium by Shelbourne and Nash, we have at the moment only natural fish adapted to a natural environment.

The choice of fish for an ecological study of the problems involved in fish farming is limited to those likely to be commercially useful, and the possible success of the hatchery programmes described by Shelbourne and Nash provides a pointer. Although it would be preferable to use a herbivorous fish, the only suitable species, the grey mullet, is at the northern limit of its range in Scottish waters. Further, a major difficulty is that its breeding habits are very little known as these probably occur in deep water. Thus, one turns to carnivorous fish and in particular to the plaice which has been successfully reared from the egg by Shelbourne. Our work so far, in the Ist year of our research, has concentrated on the plaice and on its ist year of life. It is intended to extend this and also it is hoped that this study will demonstrate the general problems facing such a change from a natural to an artificial environment.

The problems that need to be considered can be grouped under three main headings. Firstly, those concerned with food supply and therefore with the growth rate of the fish. Secondly, there is the predation on the stock of fish in its natural environment and the prevention of this within an enclosure. Thirdly, there are the problems of any parasites and diseases which may affect the fish, not only in its natural environment but especially in any artificial enclosure that may be used. In studying 
these problems we have compared two situations: the natural stock of fish in its natural environment and the transfer of natural fish to a type of environment that might result from enclosure in a pond, particularly the effects of high stocking densities. The first of these is of course a normal type of ecological problem. The second, however, requires the use of artificial enclosures and for economic reasons we have had to rely on relatively small-scale work in tanks. These tanks are $\mathrm{I} 2 \mathrm{ft}$ by $6 \mathrm{ft}$ in size and the bottom can be filled with natural substrate containing the animals on which the fish feed. The sides, which are $\mathrm{I} f t$ high, and the top, are made of fine mesh which is intended to keep in the fish and to exclude predators.

In our study of the natural population we have obtained estimates of the population size throughout the year and also a knowledge of their food requirements. An increase in population in May/June is the result of recruitment; thereafter there is a very rapid decrease in population with a mortality of about $45 \%$ per month. The maximum natural density in June was one fish $/ \mathrm{m}^{2}$, decreasing to less than $0 . \mathrm{I}$ by October. In spite of growth, the food requirements of this population showed a marked decrease from June till October. The questions that arise are whether these decreases are due to a lack of food, to disease decimating the stock, or finally to predation. The tank experiments were designed to elucidate these questions.

In the natural environment of a sandy bay tanks were stocked with different densities of young plaice and put on the bottom at the end of June. Tanks were then raised, 4, II and I 8 weeks later, and each tank was sampled for all the fish in it. The highest initial stock density of fifteen fish $/ \mathrm{m}^{2}$ fell to about nine after 4 weeks but decreased little thereafter. The lowest stocking density of $\mathrm{I} \cdot 5 \mathrm{fish} / \mathrm{m}^{2}$ showed no decrease up to the I 1 th week but the tank raised at the I 8 th week had only two fish $\left(0.3 / \mathrm{m}^{2}\right)$. The growth rate of the fish at the low density was the same as that of the natural population, but the fish at the high density showed negligible growth rate over the whole period. These results suggest that the numbers of the natural population are not limited by food since a very much higher population could survive at maintenance level. Also, they would suggest that disease cannot be the limiting factor, since under such crowded conditions one would expect, if anything, a higher mortality from disease. Thus, the results from the tanks stocked at a high density appeared to confirm the conclusion that predation is the main cause of the observed decrease in the natural population. Food, however, appears to limit growth severely above the density of $1 \cdot 5 / \mathrm{m}^{2}$, which is near the maximum density of the natural population after its settlement on the bottom in June.

At the same time as these experiments were conducted in the sandy bay, exactly the same experiment was set up in the enclosed silty area at the head of Loch Ewe, where plaice are not found naturally. Again there was a sharp drop in the population of the high density tank after 4 weeks, with little change at I I weeks. However, at the I8th week no fish at all were recovered from the tank and the same was found for all the other lower density tanks. The first possibility is lack of food but we found that at both the $4^{\text {th }}$ and $\mathrm{I}$ th weeks the fish appeared to be feeding satisfactorily, even though this had meant a change to different types of food. Thus, at least we have found that the fish can adapt to a new type of bottom containing a 
different form of food supply. At the I I th week, however, there was one important difference in these fish compared with those on the sandy bottom. The fish from the tanks with the silty bottom were heavily infected by a parasitic trematode. This trematode has a life cycle going from periwinkles through fish to birds. It is likely to be much more common in sheltered, semi-enclosed areas. The infection had penetrated through the skin of the fish into various vital organs so that, although we cannot be certain, it seems reasonable to suppose that the complete mortality after the I Ith week was due largely to this disease. Apart from this particular infection, various others were observed to be much more common in fish in the enclosed area compared with those from the sandy beach and from tanks filled with sand. In such silty areas we do not normally find young plaice and this may be partly due to the presence of other predators. However, our results would suggest that perhaps the main problem that can be faced in enclosed and silty waters could arise from parasitic infection, particularly from parasites which have life cycles dependent upon organisms living in the intertidal zone.

On the credit side it appears from the tank results that, during the Ist year of life, food may be available to support populations slightly above the maximum densities observed naturally. These densities may not be far below those considered necessary for a fish farm but this is only a temporary advantage since, as the fish grow, their food requirements will increase very rapidly. Thus, in the and and succeeding years of life it is very likely that the food requirement of the fish cannot be met from food available naturally if the fish are kept at densities sufficiently high for economic purposes. It will be possible, of course, to supplement food in the pond by supplying, from outside, food such as fish offal and mussels. This, in effect, would be using the pond as a shed rather than as a field.

We are thus faced with the problem of whether, as in farming, the yield from an area of ground can be increased by fertilization. The addition of the two main nutrients required in sea water, phosphorus and nitrogen, will increase the plant yield in a pond. For plaice, however, the essential increase is that of the benthic animals upon which they feed, so we are concerned with increasing a particular part of the food chain rather than in a general proliferation of energy. At Loch Ewe, working in floating tanks, we have tried to observe the effects of an increase of nutrients in the water on the two main types of plant growth: microscopic plants living in the water, and the benthic diatoms which are attached to the sand grains. So far we have carried out two short experiments in tanks over periods of 5 weeks, one in the autumn of 1964 and another in the spring of 1965 . On both occasions there was a marked increase in the plant growth in the water, but on neither occasion was there any increase in the productivity of the benthic diatoms which may be more directly available to animals living in or on the bottom.

There has been considerable work on the productivity of benthic animals after nutrient enrichment in fresh water. The general conclusion has been that it takes about 2 years after fertilization begins before there is any sign of a major increase in the numbers of benthic animals on the bottom. In several of these experiments, although there were general increases in several true benthic species, the main 
increase that occurred was in chironomid larvae. The delay of 2 years between fertilization and benthic production requires more detailed investigation. There are two important stages: firstly, an increase in reproduction by the population to supply the increased numbers, and secondly, an increase in food requirement of this larger population. Thus fertilization will have different types of effect on the population of animals on the bottom, and to make the most rational use of fertilizers we need to know the relative importance of increased plant growth in increasing reproduction and in increasing food for the adult benthic animals. The general continuous addition of fertilizer could prove wasteful and uneconomic. In particular, a large increase in production of chironomids might seem too wasteful a form of production since these are not true members of the benthos.

To sum up, of the three factors mentioned at the beginning, predation, disease and food supply, the most obvious one, predation, is perhaps the simplest to consider. It is apparent that predatory organisms such as crabs and small round fish will have to be excluded from an enclosure. The second factor, disease, is likely to be more troublesome. So far we have identified one main source but there are probably several other parasitic infections which may be found in semi-enclosed areas and which could have as serious effects on the fish. Yet, finally, the most important factor is the food supply since for each $\mathrm{lb}$ of fish taken from the pond $6 \mathrm{lb}$ or more of food will need to be added. It is obvious that this poses the main economic problem. The provision of an outside supply of food such as fish offal, which is economic for more valuable species like rainbow trout, may not be economic for the less valuable marine fish such as plaice, or even sole. There could be practical difficulties during the large-scale production which is the basic reason for considering the more common commercial fish such as plaice or sole. At present we have insufficient knowledge to state the economics of a return to be gained from fertilization, but certainly this is the most interesting scientific and practical problem. It is possible that initial stocking densities may find sufficient food available naturally during the Ist year of life. It is also possible that the addition of fertilizer at this time would not show any benefit in increased food for about $\mathbf{I}$ or 2 years. But these two factors combined could permit an increasing supply of benthic food to become available to the fish as they grow in their 2 nd and $3^{\text {rd }}$ years, and this could provide a compatible programme of stocking and fertilization.

\section{Engineering aspects of fish farming}

\section{By W. Frazer, Department of Civil Engineering, University of Strathclyde, Glasgow}

\section{Introduction}

The civil engineer's part in a fish farming operation is to provide the means of holding fish within an area and maintaining a specified environment within this area. He also may be involved in arrangements for harvesting.

The raising or holding of freshwater species is an old established art and is practised throughout the world. In tropical areas growth rates are spectacular and there 25 (2) 4 